\title{
Convergence Theorems for the Unique Common Fixed Point of a Pair of Asymptotically Nonexpansive Mappings in Generalized Convex Metric Space
}

\author{
Chao Wang, ${ }^{1} \mathrm{Jin} \mathrm{Li}_{,}{ }^{2}$ and Daoli $\mathrm{Zhu}^{2}$ \\ ${ }^{1}$ Department of Applied Mathematics, Tongji University, Shanghai 200092, China \\ ${ }^{2}$ Department of Management Science, School of Management, Fudan University, Shanghai 200433, China \\ Correspondence should be addressed to Chao Wang, 0810102006@tongji.edu.cn and \\ Jin Li, 071025019@fudan.edu.cn
}

Received 21 September 2009; Accepted 13 December 2009

Academic Editor: Tomonari Suzuki

Copyright (c) 2010 Chao Wang et al. This is an open access article distributed under the Creative Commons Attribution License, which permits unrestricted use, distribution, and reproduction in any medium, provided the original work is properly cited.

Let $X$ be a generalized convex metric space, and let $S, T$ be a pair of asymptotically nonexpansive mappings. In this paper, we will consider an Ishikawa type iteration process with errors to approximate the unique common fixed point of $S$ and $T$.

\section{Introduction and Preliminaries}

Let $(X, d)$ be a metric space, $S, T: X \rightarrow X$ a pair of asymptotically nonexpansive mappings if there exists $a, b, c \in[0,1], a+2 b+2 c \leq 1$ such that

$$
d\left(S^{n} x, T^{n} y\right) \leq a d(x, y)+b\left[d\left(x, S^{n} x\right)+d\left(y, T^{n} y\right)\right]+c\left[d\left(x, T^{n} y\right)+d\left(y, S^{n} x\right)\right]
$$

for all $x, y \in X, n \geq 1$.

Bose [1] first defined a pair of mean nonexpansive mappings in Banach space, that is,

$$
\|S x-T y\| \leq a\|x-y\|+b[\|x-S x\|+\|y-T y\|]+c[\|x-T y\|+\|y-S x\|],
$$

(let $n=1$ in $(*)$ ), and then they proved several convergence theorems for commom fixed points of mean nonexpansive mappings. Gu and $\mathrm{Li}$ [2] also studied the same problem; they 
considered the Ishikawa iteration process to approximate the common fixed point of mean nonexpansive mappings in uniformly convex Banach space. Takahashi [3] first introduced a notion of convex metric space, which is more general space, and each linear normed space is a special example of the space. Late on, Ciric et al. [4] proved the convergence of an Ishikawa type iteration process to approximate the common fixed point of a pair of mappings (under condition (B), which is also a special example of $(*)$ ) in convex metric space. Very recently, Wang and Liu [5] give some sufficiency and necessary conditions for an Ishikawa type iteration process with errors to approximate a common fixed point of two mappings in generalized convex metric space.

Inspired and motivated by the above facts, we will consider the Ishikawa type iteration process with errors, which converges to the unique common fixed point of the pair of asymptotically nonexpansive mappings in generalized convex metric space. Our results extend and improve the corresponding results in [1-6].

First of all, we will need the following definitions and conclusions.

Definition 1.1 (see [3]). Let $(X, d)$ be a metric space, and $I=[0,1]$. A mapping $w: X^{2} \times I \rightarrow X$ is said to be convex structure on $X$, if for any $(x, y, \lambda) \in X^{2} \times I$ and $u \in X$, the following inequality holds:

$$
d(w(x, y, \lambda), u) \leq \lambda d(x, u)+(1-\lambda) d(y, u) .
$$

If $(X, d)$ is a metric space with a convex structure $w$, then $(X, d)$ is called a convex metric space. Moreover, a nonempty subset $E$ of $X$ is said to be convex if $w(x, y, \lambda) \in X$, for all $(x, y, \lambda) \in E^{2} \times I$.

Definition 1.2 (see [6]). Let $(X, d)$ be a metric space, $I=[0,1]$, and $\left\{a_{n}\right\},\left\{b_{n}\right\},\left\{c_{n}\right\}$ real sequences in $[0,1]$ with $a_{n}+b_{n}+c_{n}=1$. A mapping $w: X^{3} \times I^{3} \rightarrow X$ is said to be convex structure on $X$, if for any $\left(x, y, z, a_{n}, b_{n}, c_{n}\right) \in X^{3} \times I^{3}$ and $u \in X$, the following inequality holds:

$$
d\left(w\left(x, y, z, a_{n}, b_{n}, c_{n}\right), u\right) \leq a_{n} d(x, u)+b_{n} d(y, u)+c_{n} d(z, u)
$$

If $(X, d)$ is a metric space with a convex structure $w$, then $(X, d)$ is called a generalized convex metric space. Moreover, a nonempty subset $E$ of $X$ is said to be convex if $w\left(x, y, z, a_{n}, b_{n}, c_{n}\right) \in$ $E$, for all $\left(x, y, z, a_{n}, b_{n}, c_{n}\right) \in E^{3} \times I^{3}$.

Remark 1.3. It is easy to see that every generalized convex metric space is a convex metric space (let $c_{n}=0$ ).

Definition 1.4. Let $(X, d)$ be a generalized convex metric space with a convex structure $w$ : $X^{3} \times I^{3} \rightarrow X$, and $E$ a nonempty closed convex subset of $X$. Let $S, T: E \rightarrow E$ be a pair of asymptotically nonexpansive mappings, and $\left\{a_{n}\right\},\left\{b_{n}\right\},\left\{c_{n}\right\},\left\{a_{n}^{\prime}\right\},\left\{b_{n}^{\prime}\right\},\left\{c_{n}^{\prime}\right\}$ six sequences in $[0,1]$ with $a_{n}+b_{n}+c_{n}=a_{n}^{\prime}+b_{n}^{\prime}+c_{n}^{\prime}=1, n=1,2, \ldots$, for any given $x_{1} \in E$, define a sequence $\left\{x_{n}\right\}$ as follows:

$$
\begin{aligned}
x_{n+1} & =w\left(x_{n}, S^{n} y_{n}, u_{n}, a_{n}, b_{n}, c_{n}\right), \\
y_{n} & =w\left(x_{n}, T^{n} x_{n}, v_{n}, a_{n}^{\prime}, b_{n}^{\prime}, c_{n}^{\prime}\right),
\end{aligned}
$$


where $\left\{u_{n}\right\},\left\{v_{n}\right\}$ are two sequences in $E$ satisfying the following condition. If for any nonnegative integers $n, m, 1 \leq n<m, \delta\left(A_{n m}\right)>0$, then

$$
\max _{n \leq i, j \leq m}\left\{d(x, y): x \in\left\{u_{i}, v_{i}\right\}, y \in\left\{x_{j}, y_{j}, S y_{j}, T x_{j}, u_{j}, v_{j}\right\}\right\}<\delta\left(A_{n m}\right)
$$

where $A_{n m}=\left\{x_{i}, y_{i}, S y_{i}, T x_{i}, u_{i}, v_{i}: n \leq i \leq m\right\}$,

$$
\delta\left(A_{n m}\right)=\sup _{x, y \in A_{n m}} d(x, y)
$$

then $\left\{x_{n}\right\}$ is called the Ishikawa type iteration process with errors of a pair of asymptotically nonexpansive mappings $S$ and $T$.

Remark 1.5. Note that the iteration processes considered in $[1,2,4,6]$ can be obtained from the above process as special cases by suitably choosing the space, the mappings, and the parameters.

Theorem 1.6 (see [5]). Let E be a nonempty closed convex subset of complete convex metric space $X$, and $S, T: E \rightarrow E$ uniformly quasi-Lipschitzian mappings with $L>0$ and $L^{\prime}>0$, and $F=$ $F(S) \cap F(T) \neq \emptyset(F(T)=\{x \in X: T x=x\})$. Suppose that $\left\{x_{n}\right\}$ is the Ishikawa type iteration process with errors defined by (1.4), $\left\{u_{n}\right\},\left\{v_{n}\right\}$ satisfy (**), and $\left\{a_{n}\right\},\left\{b_{n}\right\},\left\{c_{n}\right\},\left\{a_{n}^{\prime}\right\},\left\{b_{n}^{\prime}\right\},\left\{c_{n}^{\prime}\right\}$ are six sequences in $[0,1]$ satisfying

$$
a_{n}+b_{n}+c_{n}=a_{n}^{\prime}+b_{n}^{\prime}+c_{n}^{\prime}=1, \quad \sum_{n=0}^{\infty}\left(b_{n}+c_{n}\right)<\infty
$$

then $\left\{x_{n}\right\}$ converge to a fixed point of $S$ and $T$ if and only if $\lim _{\inf _{n \rightarrow \infty}} d\left(x_{n}, F\right)=0$, where $d(x, F)=\inf \{d(x, p): p \in F\}$.

Remark 1.7. Let $F(T)=\{x \in X: T x=x\} \neq \emptyset$. A mapping $T: X \rightarrow X$ is called uniformly quasi-Lipshitzian if there exists $L>0$ such that

$$
d\left(T^{n} x, p\right) \leq L d(x, p)
$$

for all $x \in X, p \in F(T), n \geq 1$.

\section{Main Results}

Now, we will prove the strong convergence of the iteration scheme (1.4) to the unique common fixed point of a pair of asymptotically nonexpansive mappings $S$ and $T$ in complete generalized convex metric spaces.

Theorem 2.1. Let $E$ be a nonempty closed convex subset of complete generalized convex metric space $X$, and $S, T: E \rightarrow E$ a pair of asymptotically nonexpansive mappings with $b \neq 0$, and $F=F(S) \cap$ 
$F(T) \neq \emptyset$. Suppose $\left\{x_{n}\right\}$ as in (1.4), $\left\{u_{n}\right\},\left\{v_{n}\right\}$ satisfy $(* *)$, and $\left\{a_{n}\right\},\left\{b_{n}\right\},\left\{c_{n}\right\},\left\{a_{n}^{\prime}\right\},\left\{b_{n}^{\prime}\right\},\left\{c_{n}^{\prime}\right\}$ are six sequences in $[0,1]$ satisfying

$$
a_{n}+b_{n}+c_{n}=a_{n}^{\prime}+b_{n}^{\prime}+c_{n}^{\prime}=1, \quad \sum_{n=0}^{\infty}\left(b_{n}+c_{n}\right)<\infty,
$$

then $\left\{x_{n}\right\}$ converge to the unique common fixed point of $S$ and $T$ if and only if $\lim \inf _{n \rightarrow \infty} d\left(x_{n}, F\right)=$ 0 , where $d(x, F)=\inf \{d(x, p): p \in F\}$.

Proof. The necessity of conditions is obvious. Thus, we will only prove the sufficiency.

Let $p \in F$, for all $x \in E$,

$$
\begin{aligned}
d\left(S^{n} x, p\right) & \leq a d(x, p)+b\left[d\left(x, S^{n} x\right)+d(p, p)\right]+c\left[d(x, p)+d\left(p, S^{n} x\right)\right] \\
& \leq a d(x, p)+b\left[d(x, p)+d\left(p, S^{n} x\right)\right]+c\left[d(x, p)+d\left(p, S^{n} x\right)\right]
\end{aligned}
$$

implies

$$
(1-b-c) d\left(S^{n} x, p\right) \leq(a+b+c) d(x, p)
$$

which yield (using the fact that $a+2 b+2 c \leq 1$ and $b \neq 0$ )

$$
d\left(S^{n} x, p\right) \leq K d(x, p)
$$

where $0<K=(a+b+c) /(1-b-c) \leq 1$. Similarly, we also have $d\left(T^{n} x, p\right) \leq K d(x, p)$.

By Remark 1.7, we get that $S$ and $T$ are two uniformly quasi-Lipschitzian mappings (with $L=L^{\prime}=K>0$ ). Therefore, from Theorem 1.6, we know that $\left\{x_{n}\right\}$ converges to a common fixed point of $S$ and $T$. have

Finally, we prove the uniqueness. Let $p_{1}=S p_{1}=T p_{1}, p_{2}=S p_{2}=T p_{2}$, then, by $(*)$, we

$$
\begin{aligned}
d\left(p_{1}, p_{2}\right) & \leq a d\left(p_{1}, p_{2}\right)+b\left[d\left(p_{1}, p_{1}\right)+d\left(p_{2}, p_{2}\right)\right]+c\left[d\left(p_{1}, p_{2}\right)+d\left(p_{1}, p_{2}\right)\right] \\
& \leq(a+2 c) d\left(p_{1}, p_{2}\right) .
\end{aligned}
$$

Since $a+2 c<1$, we obtain $p_{1}=p_{2}$. This completes the proof.

Remark 2.2. (i) We consider a sufficient and necessary condition for the Ishikawa type iteration process with errors in complete generalized convex metric space; our mappings are the more general mappings (a pair of asymptotically nonexpansive mappings), so our result extend and generalize the corresponding results in $[1-4,6]$.

(ii) Since $\left\{x_{n}\right\}$ converges to the unique fixed point of $S$ and $T$, we have improved Theorem 1.6 in [5]. 
Corollary 2.3. Let E be a nonempty closed convex subset of Banach space $X, S, T: E \rightarrow E$ a pair of asymptotically nonexpansive mappings, that is,

$$
\left\|S^{n} x-T^{n} y\right\| \leq a\|x-y\|+b\left[\left\|x-S^{n} x\right\|+\left\|y-T^{n} y\right\|\right]+c\left[\left\|x-T^{n} y\right\|+\left\|y-S^{n} x\right\|\right]
$$

with $b \neq 0$, and $F=F(S) \cap F(T) \neq \emptyset$. For any given $x_{1} \in E,\left\{x_{n}\right\}$ is an Ishikawa type iteration process with errors defined by

$$
\begin{gathered}
x_{n+1}=a_{n} x_{n}+b_{n} S^{n} y_{n}+c_{n} u_{n}, \\
y_{n}=a_{n}^{\prime} x_{n}+b_{n}^{\prime} T^{n} x_{n}+c_{n}^{\prime} v_{n},
\end{gathered}
$$

where $\left\{u_{n}\right\},\left\{v_{n}\right\} \in E$ are two bounded sequences and $\left\{a_{n}\right\},\left\{b_{n}\right\},\left\{c_{n}\right\},\left\{a_{n}^{\prime}\right\},\left\{b_{n}^{\prime}\right\},\left\{c_{n}^{\prime}\right\}$ are six sequences in $[0,1]$ satisfying

$$
a_{n}+b_{n}+c_{n}=a_{n}^{\prime}+b_{n}^{\prime}+c_{n}^{\prime}=1, \quad \sum_{n=1}^{\infty}\left(b_{n}+c_{n}\right)<\infty
$$

Then, $\left\{x_{n}\right\}$ converges to the unique common fixed point of $S$ and $T$ if and only if $\lim \inf _{n \rightarrow \infty} d\left(x_{n}, F\right)=0$, where $d(x, F)=\inf \{\|x-p\|: p \in F\}$.

Proof. From the proof of Theorem 2.1, we have

$$
\left\|S^{n} x-p\right\| \leq K\|x-p\|, \quad\left\|T^{n} x-p\right\| \leq K\|x-p\|
$$

where $K=(a+b+c) /(1-b-c)$. Hence, $S$ and $T$ are two uniformly quasi-Lipschitzian mappings in Banach space. Since Theorem 1.6 also holds in Banach spaces, we can prove that there exists a $p \in F$ such that $\lim _{n \rightarrow \infty}\left\|x_{n}-p\right\|=0$. The proof of uniqueness is the same to that of Theorem 2.1. Therefore, $\left\{x_{n}\right\}$ converges to the unique common fixed point of $S$ and $T$.

Corollary 2.4. Let E be a nonempty closed convex subset of Banach space $X, S, T: E \rightarrow E$ a pair of asymptotically nonexpansive mappings, that is,

$$
\left\|S^{n} x-T^{n} y\right\| \leq a\|x-y\|+b\left[\left\|x-S^{n} x\right\|+\left\|y-T^{n} y\right\|\right]+c\left[\left\|x-T^{n} y\right\|+\left\|y-S^{n} x\right\|\right]
$$

with $b \neq 0$, and $F=F(S) \cap F(T) \neq \emptyset$. For any given $x_{1} \in E,\left\{x_{n}\right\}$ an Ishikawa type iteration process defined by

$$
\begin{gathered}
x_{n+1}=\alpha_{n} x_{n}+\left(1-\alpha_{n}\right) S^{n} y_{n}, \\
y_{n}=\beta_{n} x_{n}+\left(1-\beta_{n}\right) T^{n} x_{n},
\end{gathered}
$$

where $\left\{\alpha_{n}\right\},\left\{\beta_{n}\right\}$ are two sequences in $[0,1]$ satisfying $\sum_{n=1}^{\infty}\left(1-\alpha_{n}\right)<\infty$. Then, $\left\{x_{n}\right\}$ converges to the unique common fixed point of $S$ and $T$ if and only if $\lim _{\inf } \operatorname{in}_{n \rightarrow \infty} d\left(x_{n}, F\right)=0$, where $d(x, F)=$ $\inf \{\|x-p\|: p \in F\}$. 
Proof. Let $a_{n}=\alpha_{n}, a_{n}^{\prime}=\beta_{n}$ and $c_{n}=c_{n}^{\prime}=0$. The result can be deduced immediately from Corollary 2.3. This completes the proof.

\section{Acknowledgments}

The authors would like to thank the referee and the editor for their careful reading of the manuscript and their many valuable comments and suggestions. The research was supported by the Natural Science Foundation of China (no. 70432001) and Shanghai Leading Academic Discipline Project (B210).

\section{References}

[1] S. C. Bose, "Common fixed points of mappings in a uniformly convex Banach space," Journal of the London Mathematical Society, vol. 18, no. 1, pp. 151-156, 1978.

[2] Z. Gu and Y. Li, "Approximation methods for common fixed points of mean nonexpansive mapping in Banach spaces," Fixed Point Theory and Applications, vol. 2008, Article ID 471532, 7 pages, 2008.

[3] W. Takahashi, "A convexity in metric space and nonexpansive mappings. I," Kodai Mathematical Seminar Reports, vol. 22, pp. 142-149, 1970.

[4] L. B. Ciric, J. S. Ume, and M. S. Khan, "On the convergence of the Ishikawa iterates to a common fixed point of two mappings," Archivum Mathematicum, vol. 39, no. 2, pp. 123-127, 2003.

[5] C. Wang and L. W. Liu, "Convergence theorems for fixed points of uniformly quasi-Lipschitzian mappings in convex metric spaces," Nonlinear Analysis: Theory, Methods E Applications, vol. 70, no. 5, pp. 2067-2071, 2009.

[6] Y.-X. Tian, "Convergence of an Ishikawa type iterative scheme for asymptotically quasi-nonexpansive mappings," Computers E Mathematics with Applications, vol. 49, no. 11-12, pp. 1905-1912, 2005. 